\title{
QUALIDADE DE VIDA N(D)O TRABALHO: UM CONCEITO POLÍTICO E POLISSÊMICO
}

\author{
QUALITY OF LIFE OF/AT WORK: A POLITICAL AND POLYSEMIC CONCEPT
}

Francisco Antonio de Castro Lacaz ${ }^{1}$

Resumo Neste texto objetiva-se chamar atenção para a historicidade e a polissemia do conceito de Qualidade de Vida n(d)o trabalho (QVT) ou, melhor dizendo, Qualidade do Trabalho (QT) e seu caráter político, na medida em que envolve interesses de classe contraditórios; na perspectiva de colocá-lo num patamar de discussão que questiona a abordagem 'clínica' comumente adotada pelo capital e que coloca como principal estratégia a mudança de 'hábitos' dos indivíduos. Assim, desloca-se a discussão para a categoria 'controle' sobre os processos de trabalho, na perspectiva dos coletivos de trabalhadores, o que permite articular o conceito à noção de que atingir a QVT envolve um embate político que é dado pela correlação de forças capital-trabalho, em sociedades concretas. Neste sentido, mesmo que se considere incompatível pensar em QVT numa realidade de precariedade do trabalho (e de direitos), advoga-se que a introdução no debate de um outro 'olhar' sobre a questão, o qual também tem um forte caráter político, contra-hegemônico, pode contribuir para o enfrentamento do 'discurso único' e da prática a ele acoplada, as quais são defendidas como sendo 'o' modelo de abordagem da QVT por parte das empresas e dos intelectuais da própria academia que as assessoram.

Palavras-chave trabalho; qualidade total; controle; processo de trabalho; neoliberalismo.
Abstract In this paper we aim to draw attention to the historicity and the polysemy of the concept of Quality of Life at (of) work (QWL), or rather, Quality of Work (QW) and its political nature, as it involves contradictory class interests, with the idea of placing it at a level of discussion that questions the 'clinical' approach commonly adopted by capital and that designates individuals' change of habits as the main strategy. Thus, the discussion shifts to the category 'control' over the work processes in the point of view of workers' collectives allowing a relation between the concept and the notion that achieving QWL involves a political struggle that is originates from the correlation of the capital-labor strengths in concrete societies. In this sense, even if it is deemed incompatible to think of QWL as a reality of precarious work (and rights), this article advocates that the introduction of another 'vision' concerning this issue, which also has a strong political and counter-hegemonic character, can contribute to addressing the 'speech' and the skills that come along with it, the ones which are defended as being 'the' model approach of QWL by businesses and the intellectuals from the academy that advise them.

Keywords work, total quality, control, work process, neoliberalism. 


\section{A historicidade da qualidade de vida $\mathrm{n}(\mathrm{d})$ o trabalho}

O ponto de partida aqui assumido é que, para dialogar com o texto de Padilha (2009), importa, historicamente, apontar como a abordagem da Qualidade de Vida $\mathrm{n}(\mathrm{d}) \mathrm{o}$ Trabalho (QVT) vem ocorrendo e como se coloca na perspectiva do embate e da correlação de forças entre Capital-Trabalho e da sua relação com a Saúde no Trabalho.

O que se propõe é dar visibilidade à historicidade do conceito, ao transitarse dos anos 50 do século passado até os 2000, assinalando seus aspectos marcantes.

Pode-se apontar como um marco que a discussão desta temática surge no final dos anos 1950, relacionando-se com experiências de trabalho as quais são vivenciadas por coletivos de trabalhadores na perspectiva de um patamar de produtividade por eles regulado (Lacaz, 2000).

Nos anos 1960-70 tal caminho aprofunda-se e a QVT relaciona-se à busca pela qualidade das condições, ambientes e organização do trabalho, numa perspectiva classista visando maior satisfação laboral, o que, em última instância, também se relaciona com a produtividade regulada. Frise-se que tal visão é influenciada e alimentada por movimento originado no 'chão de fábrica', especialmente na Europa, no qual a 'gestão participativa' e a 'democracia industrial' são ideais a serem conquistados e garantidos (Bagnara, Biocca e Mazzonis, 1981; Roustang, 1983; 1982; Antunes, 1999).

É justamente neste contexto que, em meados dos anos 1970, mais precisamente em 1976, a Organização Internacional do Trabalho (OIT) lança o Programa Internacional para o Melhoramento das Condições de Trabalho (Piact), o qual preconizava a melhoria geral de vida como aspiração da humanidade, melhoria esta que não pode ser barrada no portão da fábrica, o que tinha como pressuposto a participação dos trabalhadores nas decisões relativas à sua vida e às suas atividades laborais (Mendes, 1986).

A partir dos anos 1980, o enfoque da globalização e da reestruturação produtiva passa a influenciar a visão de QVT, quando busca dar conta de questões relacionadas à produtividade, mas agora articulada com a qualidade do produto e a competitividade, o que envolve a motivação, o pertencimento à empresa como algo intrínseco à produção capitalista, ao que se soma a saúde no trabalho, considerando aspectos relativos a formas diferenciadas de organização do trabalho e a novas tecnologias de gestão do trabalho. Tal enfoque vai se aprofundar nos anos 1990 e 2000 (Lacaz, 2000).

De certa forma, a relevância desta discussão relaciona-se com o esgotamento da organização do trabalho taylorista/fordista que se associava ao aumento do absenteísmo, ao mal-estar no trabalho e à não aderência dos trabalhadores às metas definidas pela gerência (Antunes, 1999). Agora, o modelo japonês, o toyotismo, é o novo paradigma de organização do trabalho a ser implantado (Antunes, 1995; Gorender, 1997). 


\section{Questões para reflexão}

Duas questões devem ser aqui ressaltadas, a propósito do texto de Padilha (2009): sua preocupação com a pertinência de advogar a QVT numa realidade de precarização do trabalho e, de outro lado, o que se deve valorizar considerando a relação entre QVT e a Saúde no Trabalho.

Se pode-se concordar com a autora de que a existência da QVT de caráter finalista é incompatível com o sócio metabolismo do capital, não é menos válido afirmar que não cabe esperar o fim do capitalismo para pensar-se a QVT numa perspectiva progressista. Por que não, por exemplo, discutir a qualidade do trabalho considerando as estratégias defendidas pelo próprio capital, ao adotar as normas ISO para qualificar os produtos, as quais, via de regra, não levam em consideração a qualidade dos processos de trabalho?

Ademais, se, a princípio, o discurso da qualidade hoje veiculado, dá a impressão de que a ideologia gerencial é eficaz, já que a ninguém escapa a necessidade de se trabalhar com qualidade, podendo parecer que os trabalhadores comungam dos mesmos interesses da gerência, empresários e consumidores dos produtos de qualidade, isto é somente a aparência. Aparência esta que se desmancha no ar quando é observada a variada gama de atributos que a noção de qualidade encerra, possibilitando que sob o mesmo signo sejam defendidos interesses de classe os mais variados ou mesmo opostos, já que para os 'patrões pós-fordistas' 2 trabalhar com qualidade pressupõe economia de tempo, de pessoas e de materiais; enquanto para os trabalhadores que buscam negociar maior controle do processo de trabalho, significa diminuição do ritmo de funcionamento do maquinário, por exemplo (Sato, 2002).

Frise-se que esta nova realidade de gestão do trabalho, embutida na flexibilização produtiva, caracteriza-se por uma 'consciência apologética' que decreta

(...) o fim das relações antagônicas entre capital e trabalho, que estão sendo substituídas por relações de cooperação e de amizade entre parceiros. (...) acredita [-se] que a reestruturação da economia está a criar novas formas de organização e gerenciamento do processo de trabalho, que não lembram mais os princípios de padronização, especialização, sincronização e de centralização que configuravam e alicerçavam a estruturação do processo produtivo. No lugar da produção padronizada, surge a produção flexível que requer (...) trabalhadores polivalentes e altamente qualificados, com alto grau de responsabilidade e autonomia (Teixeira, 2008, p. 114-5).

Mais ainda,

(...) esta nova forma de produção de mercadorias engendra outros métodos de produção (...) Com a diferença de que, agora, o poder do capital é substituído pelo poder impessoal do mercado. Poder que não mais se identifica com a administração 
de uma empresa particular, mas, sim, com a necessidade abstrata que obriga todos a se submeterem à racionalidade do trabalho abstrato: trabalhar (...), sem se importar com a natureza do trabalho, o lugar em que é realizado e como deve ser efetivado (Teixeira, 2008, p. 131).

Assim, um novo desafio coloca-se, ou seja, a superação do 'discurso único', de caráter apologético, para que possa ocorrer a negociação, pressupondo o reconhecimento de conflitos e diferenças de interesses, o que a racionalidade capitalista pós-fordista procura incessantemente desfigurar ao apregoar que todos são empreendedores e colaboradores que 'vestem a mesma camisa'. Assim, no contexto da gestão pós-fordista até a identificação das diferenças de interesses é algo que deve ser priorizado na luta política pela busca da qualidade no trabalho do ponto de vista dos trabalhadores.

Advoga-se aqui, também, que o enfoque da QVT, relacionado à Saúde no Trabalho, uma outra dentre as preocupações de Padilha (2009), deve ser discutido a partir das contribuições do campo de práticas e conhecimentos Saúde do Trabalhador (Lacaz, 1996; Minayo-Gomes e Thedim-Costa, 2003), na medida em que permite pensar numa perspectiva mais holística tal relação, mediada pela categoria processo de trabalho, conceito central apreendido pelo campo e que vai possibilitar uma explicação mais aprofundada do quadro de morbi-mortalidade ligado ao trabalho na contemporaneidade, em que as doenças relacionadas ao trabalho apresentam um novo perfil de ocorrência pelo predomínio dos distúrbios mentais, das doenças psicossomáticas e cardiocirculatórias (Lacaz, 2000).

Frise-se que o conceito de processo de trabalho ao articular objeto de trabalho, instrumentos de trabalho e o próprio trabalho à gestão, considerando suas formas históricas e peculiares de organização (Marx, 1980; Laurell e Noriega, 1989; Laurell, 1993), permite ponderar que componentes do mesmo são mais decisivos para que se concretize a QVT contra-hegemônica.

Na verdade, como sugerem Laurell e Noriega (1989), a abordagem em Saúde do Trabalhador assume que, na análise do processo saúde-doença, o trabalho tem um papel fundamental em sua determinação, e trata-se, então, de desvendar esta realidade e buscar a interlocução com os trabalhadores vistos agora como agentes coletivos e portadores de conhecimentos e práticas, que possibilitam pensar-se na humanização do trabalho e no seu ethos, mesmo considerando que se atua dentro dos limites e marcos do capitalismo. Trata-se de se pensar táticas e estratégias para avançar na luta pela qualidade no trabalho.

Ademais, seria algo impensado jogar por terra toda a produção científica calcada na abordagem advogada pelo campo Saúde do Trabalhador, a qual foi construída com a contribuição da Medicina Social latino-americana (Laurell, 1991 e 1993; Breilh, 1994), da Saúde Coletiva e da própria Saúde 
Pública (Lacaz, 1996; Minayo-Gomes e Thedim-Costa, 2003), porque se situa nos marcos do capitalismo periférico. Neste sentido, é necessário relativizar afirmações que situam no "teatro da humanização do trabalho" (Araújo, 2008, apud Padilha, 2009) propostas de lutar pela democratização das relações sociais no trabalho numa visão crítica do embate de classes.

Sabe-se que a questão fundamental neste embate político, que envolve inclusive a busca da qualidade do trabalho autêntica, é a superação da cisão operada pela lógica de produção capitalista apontada por Marx entre concepção e execução do trabalho.

A citação abaixo coloca-nos um desafio, como será apontado no parágrafo seguinte:

(...) o homem só pode ser verdadeiramente livre quando se livrar das coações externa e internas, físicas e morais - que compõem a sociedade capitalista (...) Para que o tempo livre seja verdadeiro e cheio de sentido, o rompimento com a lógica do capital e com a sociedade fundada no mercado é decisivo (Padilha, 2000, p. 15, apud Padilha, 2009).

No limite o que está colocado é a impossibilidade de no capitalismo viver-se em democracia como aponta importante obra de Wood (2003), no que é corroborada por Chauí (2001) a propósito da realidade brasileira.

Tal assertiva é trabalhada por Bóron (2000) na perspectiva de que podemos falar de conjunturas políticas em que há uma adjetivação, ou seja, um certo 'capitalismo democrático', como ocorreu com a experiência socialdemocrática vivida em alguns países do capitalismo central. Nem por isso, deixou-se de lutar pela ampliação de espaços de participação dentro das relações sociais de produção ali existentes.

Assim, ao se cotejar uma concepção de QVT que se contrapõe à visão hegemônica defendida pela gerência capitalista, a qual tem sua base de atuação na aparência dos problemas, propondo técnicas de relaxamento, ginástica laboral, meditação, o que recoloca em pauta a culpabilização da vítima, estratégia esta subsidiada por inúmeros artigos, teses e livros (França, 1996; 1999; França e Albuquerque, 1998; França e Rodrigues, 1999; Zavattaro, 2001), cabe questionar esta abordagem.

É dentro desta verdadeira guerra de posições que se coloca a necessidade de se redirecionar o foco deste debate como propomos em artigo publicado há alguns anos (Lacaz, 2000). Frise-se que a 'provocação' nele contida foi bastante citada por autores que não concordavam com a visão reducionista e parcial prevalecente, abrindo espaço para uma rediscussão da temática.

É justamente nesta seara que se pode atuar, na perspectiva de uma acumulação de forças para o embate mais estratégico. 
A título de conclusão deste texto-debate, é mister ressaltar e reafirmar que as questões aqui colocadas têm como pano de fundo a noção de QVT a partir de um referencial que coloca como aspecto central, para que seja buscada a referida qualidade, a concepção de controle que os coletivos de trabalhadores devem ter sobre seus processos de trabalho (Lacaz, 2000; Lacaz e Sato, 2006). Postula-se, então, que tais referenciais e abordagens podem fazer avançar a profundidade dos estudos nesta área.

Isto implica dizer que não se está assumindo uma posição ingênua sobre os possíveis alcances de tal estratégia, mas sim de afirmar, parafraseando o Fórum Social Mundial, de que uma 'outra QVT é possível'.

A escolha dos interlocutores que podem se somar à luta para alcançá-la parece ser a questão central que se coloca como um desafio para os militantes da superação do despotismo capitalista, sob pena de cair-se num imobilismo estéril!

\section{Notas}

1 Professor associado II do Departamento de Medicina Preventiva da Universidade Federal de São Paulo (Unifesp). Pós-Doutorado pela Universidade Autônoma de Barcelona. Doutorado em Saúde Coletiva pela Universidade Estadual de Campinas (Unicamp), Brasil. $<$ f.lacaz@unifesp.br> Correspondência: Rua Afonso Celso, 718, apto. 12, São Paulo, SP, Brasil, CEP 04119-060.

2 Com a terminologia 'patrões pós-fordistas', está se referindo, conforme a proposição de Gorender (1997), às situações de trabalho que adotam o toyotismo que, para ele, nada mais é do que uma 'adaptação' do fordismo.

\section{Referências}

ANTUNES, Ricardo. Adeus ao trabalho?: ensaio sobre as metamorfoses e a centralidade do mundo do trabalho. São Paulo: Cortez; Campinas: Editora Unicamp; 1995. 155 p.

Os sentidos do trabalho: ensaios sobre a afirmação e a negação do trabalho. São Paulo: Boitempo Editorial, 1999. 285 p.
BAGNARA, Sergio.; BIOCCA, Marco; MAZZONIS, Diego G. Trends in Occupational Health and Safety Policy in Italy. International Journal of Health Services, v. 11, n. 3, p. 431-450, 1981.

BORÓN, Atílio. Os 'novos Leviatãs' e a pólis democrática: neoliberalismo, decomposição estatal e decadência da democracia na 
América Latina. In: SADER, Emir e GENTILI, Pablo. (Orgs.) Pós-neoliberalismo II: que Estado e que democracia?. 2. ed. Petrópolis: Vozes, p. 7-67, 2000, 182 p.

CHAUÍ, Marilena. Introdução: a universidade na sociedade. In: . Escritos sobre a universidade. São Paulo: Editora Unesp, 2001, p. 9-41. 133 p.

FRANÇA, Ana Cristina L. Indicadores empresariais de Qualidade de Vida: esforço empresarial e satisfação dos empregados no ambiente de manufaturas com certificação ISO 9000. Tese (Doutorado em Administração de Empresas) - FEA/USP, São Paulo, 1996.

FRANÇA, Ana Cristina L.; RODRIGUES, Antonio L. Stress e trabalho. 2. ed. São Paulo: Atlas, 1999.

FRANÇA, Ana Cristina L.; ALBUQUERQUE, Luiz G. Estratégias de Recursos Humanos e Gestão da Qualidade de Vida no Trabalho: o stress e a expansão do conceito de qualidade total. Revista de Administração, São Paulo, abr./jun. 1998.

GORENDER, Jacob. Globalização, tecnologia e relações de trabalho. Estudos Avançados, v. 29, n. 11, p. 311-361, 1997.

LACAZ, Francisco A. C. Saúde do trabalhador: um estudo sobre as formações discursivas da academia, dos serviços e do movimento sindical. 435 p. Tese.(Doutorado em Medicina, área Saúde Coletiva) - Faculdade de Ciências Médicas da Universidade Estadual de Campinas, 1996. XXI p. +423 p.

Qualidade de Vida no Trabalho e saúde-doença. Ciência \& Saúde Coletiva, v. 5, n. 1, p. 151-161, 2000.

LACAZ, Francisco A. C.; SATO, Leny. Humanização e qualidade do processo de trabalho em saúde. In: Deslandes, Sueli F. (org.) Humanização dos cuidados em saúde: conceitos, dilemas e críticas. Rio de Janeiro: Editora Fiocruz, p. 109-139, 2006. 433 p.

LAURELL, Asa. C. Trabajo y salud: estado del conocimiento. In: FRANCO, Saul NUNES,
Everardo D.; BREILH, Jaime; LAURELL, Asa C. (Orgs.) Debates en Medicina Social. Quito: Organización Panamericana de la Salud/ Associación Latinoamericana de Medicina Social, p. 249-339, 1991. 339 p.

(Coord.) Para la investigación sobre la salud de los trabajadores. Washington: Opas, 1993.

LAURELL, Asa C.; NORIEGA, Mariano. Processo de produção e saúde: trabalho e desgaste operário. São Paulo: Cebes-Hucitec, 1989. 385 p.

MARX, Karl. O capital. Crítica da Economia Política. Livro Primeiro. O processo de produção do capital. Volume I, Capítulo V. Rio de Janeiro: Civilização Brasileira, 1980.

MENDES, René. Doutrina e prática da integração da Saúde Ocupacional no setor saúde: contribuição para a definição de uma política. Tese (Livre Docência). Departamento de Saúde Ambiental, Faculdade de Saúde Pública, Universidade de São Paulo, 1986.

MINAYO-GOMEZ, Carlos; THEDIM-COSTA, Sonia M. F. Incorporação das ciências sociais na produção de conhecimento sobre trabalho e saúde. Ciência \& Saúde Coletiva, v. 8 , n. 1, p. 125-136, 2003.

PADILHA, Valquíria. Qualidade de Vida no Trabalho num contexto de precarização: a panaceia delirante. Trabalho, Educação e Saúde, Rio de Janeiro, p. 549-563, nov. 2009/ fev. 2010.

ROUSTANG, Gaston. Os trabalhadores e a higiene e segurança na França. Revista Internacional do Trabalho, v. 102, n. 2, p. 247261, 1983.

SATO, Leny. A prevenção dos agravos à saúde do trabalhador: replanejando o trabalho através das negociações cotidianas. Cadernos de Saúde Pública, v. 18, n. 5, p. 1147-1166, 2002.

TEIXEIRA, Francisco. Marx, ontem e hoje. In: TEIXEIRA, F.; FREDERICO, C. Marx no 
século XXI. São Paulo: Cortez, p. 29-139, ZAVATTARO, Heli A. A Qualidade de Vida 2008. 197 p. no Trabalho de profissionais da área de informática: um estudo exploratório. Dissertação WOOD, Ellen M. Democracia contra o capitalismo: a renovação do materialismo histórico. São Paulo: Boitempo Editorial, 2003. 261 p. (Mestrado em Psicologia Social) - Instituto de Psicologia da Universidade de São Paulo, 1999. 